\title{
ВЛИЯНИЕ СОСТАВА ФТОРКАУЧУКОВ НА СВОЙСТВА ИХ ВУЛКАНИЗАТОВ
}

\author{
И. П. Трифонова, А.С. Симонов, Ю.А. Родичева, В.В. Александрийский, \\ В.А. Бурмистров, О.И. Койфман
}

ИРИНА ПАВЛОВНА ТРИФОНОВА - к.х.н., дочент кафедры химии и технологии высокомолекулярных веществ (ХиТВМС) ФГБОУВО ИГХТУ.E-mail: trifonova@isuct.ru.

\author{
АЛЕКСАНДР СЕРГЕЕВИЧ СИМОНОВ - магистрант кафедры ХиТВМС ФГБОУ ВО ИГХТУ. \\ E-mail: aleksandr_simonov_2011@mail.ru. \\ ЮЛИЯ АЛЕКСАНДРОВНА РОДИЧЕВА - к.х.н., н.с. кафедры ХиТВМС ФГБОУ ВО ИГХТУ. \\ E-mail: rodichevajulia@mail.ru.
}

ВИКТОР ВЕНИАМИНОВИЧ АЛЕКСАНДРИЙСКИЙ - д.х.н., в. н.с. кафедры ХиТВМС ФГБОУ ВО ИГХТУ. E-mail:nmr@isuct.ru.

ВЛАДИМИР АЛЕКСАНДРОВИЧ БУРМИСТРОВ - д.х.н., профессор кафедры ХиТВМС ФГБОУ ВО ИГХТУ. E-mail: burmistrov@isuct.ru.

ОСКАР ИОСИФОВИЧ КОЙФМАН - чл.-корр. РАН, д.х.н., президент ИГХТУ, зав. кафедрой ХиТВМС ФГБОУ ВО ИГХТУ. E-mail: president@isuct.ru.

153000, Иваново, Шереметевский проспект, д. 7, Ивановский государственный химико-технологический университет (ФГБОУ ВО ИГХТУ), Кафедра химии и технологии высокомолекулярных соединений (XuTBMC).

Квантово-химическим методом проведена оценка молекулярной поляризуемости и дипольньх моментов фрагментов сополимерных фторкаучуков. Показано, что полярность фторкаучуков обеспечивается присутствием винилиденфторидных звеньев.

Методом динамического механического анализа получены частотные и температурные зависимости модуля упругости Е' и тангенса угла механических потерь tg $\delta$ фторкаучуков и вулканизатов на их основе. Установлены особенности влияния состава каучуков и вулканизации на механические и теплофизические характеристики эластомеров. Получень значения прочности при растяжении и удлинения при разрыве вулканизатов исследованных фторкаучуков, а также вязкости по Муни и остаточной деформации при сжатии. Установлено, что решающее влияние на эти параметры оказывают полярность каучука и параметры вулканизациионной сетки.

Изучена кинетика набухания каучуков и резин на их основе в 1,2-дихлорэтане при $50{ }^{\circ} \mathrm{C}$. Проведена оценка степени ограничения сорбции растворителя при возникновении вулканизационной сетки, а также ее параметры. Установлено, что эластомеры по снижению их равновесной степени и скорости набухания в дихлорэтане располагаются в ряду: СКФ-26> Элафтор $3061 P>$ Элафтор $7075>$ Элафтор 1000Р , симбатно уменьшению их полярности.

Ключевые слова: фторкаучук, квантово-химические расчеты, вулканизационная сетка. 


\title{
INFLUENCE OF THE FLUORINE RUBBERS ON THE PROPERTIES OF THEIR VOLCANIZATES
}

\author{
I. P. Trifonova, J.A. Rodicheva, A. S. Simonov, V.V. Aleksandriiskii, \\ V.A. Burmistrov, O. I. Koifman
}

153000, Ivanovo, Sheremetievskiy Avenue, 7. Ivanovo State University of Chemistry and Technology, Department of Chemistry and Technology of Macromolecular Compounds.

The molecular polarizability and dipole moments of copolymer fluoroelastomers fragments have been estimated by the quantum-chemical method. The polarity of fluoroelastomers was shown to be provided by the presence of vinylidene fluoride units. By the method of dynamic mechanical analysis, the frequency and temperature dependences of the storage modulus $E^{\prime}$ and the tangent of mechanical losses tg $\delta$ of fluoroelastomers and vulcanizates based on them have been obtained. The influence features of the rubbers composition and vulcanization on the mechanical and thermophysical characteristics of elastomers have been established. The values of tensile strength and elongation at break of the investigated fluoroelastomers vulcanizates, as well as Mooney viscosity and compression set were obtained. The crucial influence on these parameters was found to be exerted by the rubber polarity and the parameters of the vulcanization network. The swelling kinetics of the rubbers and vulcanizates based on them in 1,2-dichloroethane at $50{ }^{\circ} \mathrm{C}$ has been studied. The estimation of the sorption restriction upon the appearance of the vulcanization network, as well as its parameters, was carried out. It has been found that elastomers are in the following order to reduce their equilibrium degree and swelling rate in dichloroethane: SKF-26 > Elaftor 3061R > Elaftor $7075>$ Elaftor 1000R, symbate with a decrease in their polarity.

Key words: fluoroelastomer, quantum-chemical calculations, vulcanization mesh.

\section{Введение}

Фторполимеры являются наиболее термически стабильными полимерами, обладающими физической и химической устойчивостью, инертностью к кислотам, растворителям и маслам, отличной стойкостью к старению [1]. Малый размер, высокая электроотрицательность $(4,0)$ и низкая поляризуемость $(0,577)$ атомов фтора способствуют образованию прочных и стабильных ковалентных связей углерод-фтор во фторполимерах [2]. Внутримолекулярные и межмолекулярные взаимодействия между атомами водорода и фтора также способствуют повышению их физической и химической стабильности и стойкости к старению. Благодаря этому они широко используются во многих отраслях промышленности, в том числе, для изготовления теплоизоляционных материалов, прокладок, уплотнений и уплотнительных колец в нефтехимической, автомобильной, медицинской и электротехнической отраслях [1-9].

Современные марки фторэластомеров разрабатываются для того, чтобы выдерживать экстремальные условия эксплуатации в системах за- щиты, установках производства электроэнергии, а также химических и промышленных технологических установках [10-12]. В настоящее время промышленную значимость имеют три основных типа фторэластомеров - фторуглеродные, фторсиликоновые эластомеры и специальные перфторэластомеры с повышенными эксплуатационными характеристиками.

Целью данной работы является установление закономерностей влияния химического строения фторкаучуков на физико-химические, физико-механические и теплофизические свойства резин на их основе.

\section{Методика эксперимента}

\section{Объекты исследования}

Для исследований механических, теплофизических и других свойств использовали образцы каучуков производства «ГалоПолимер» Россия. Исследовались каучуки и резины на их основе: СКФ 26 (содержание фтора $67 \%$ масс., $\mathrm{T}_{\text {ст }}=-18{ }^{\circ} \mathrm{C}$ ), Элафтор 3061M (содержание фтора 68 \% масс., 
$\mathrm{T}_{\text {ст }}=-13{ }^{\circ} \mathrm{C}$ ), Элафтор 7005 (содержание фтора $70 \%$ масс., $\mathrm{T}_{\text {ст }}=-5^{\circ} \mathrm{C}$ ), Элафтор $1000 \mathrm{P}$ (содержание фтора $72 \%$ масс., $\mathrm{T}_{\text {ст }}=-3{ }^{\circ} \mathrm{C}$ ).

В составе резин на 100 масс.ч. каучука присутствуют следующие ингредиенты: наполнитель технический углерод ТУ марки N-990(30 масс. ч); акцепторы галогенводородов - ZnO (3 масс. ч), $\mathrm{MgO}$ (3 масс. ч), $\mathrm{Ca}(\mathrm{OH})_{2}$ (6 масс. ч), агент пероксидной вулканизации 2,5-Ди(трет-бутилперокси)2,5-диметилгексан (Luperox 101XL45) (3 масс. ч); соагент пероксидной вулканизации триаллилизоцианурат TAIC 70 (1,5 масс. ч).

Перемешивание резиновой смеси производилось на вальцах. Изготовление образцов в виде дисков из резины диаметром 40 мм и высотой $6,3 \pm 0,3 \mathrm{мm}$, а также пластин размерами $100 \times 100 \times 2 \pm 0,2$ мм производилось путем прямого прессования при температуре $170 \pm 10{ }^{\circ} \mathrm{C}$ на гидравлическом вулканизационном прессе с электрообогревом XLB-Y300. Затем образцы термостатировали при температуре $230{ }^{\circ} \mathrm{C}$ в течение 4 часов.

Определение вязкости по Муни на роторном дисковом вискозиметре

Согласно ГОСТ Р ИСО 289-1-2017 [13] на вискозиметре Муни МТ-204 при температуре $(100,0 \pm 0,5){ }^{\circ} \mathrm{C}$ в течение 4 мин измеряли крутящий момент. Результаты испытания регистрировали в следующем формате: $50 \mathrm{ML}(1+4) 100{ }^{\circ} \mathrm{C}$, где $50 \mathrm{M}$ - вязкость, единицы по Муни; L - указывает на использование большого ротора (S указывает на использование малого ротора); 1 - время предварительного нагрева до запуска ротора, мин; 4 - время проведения испытания после запуска ротора; $100{ }^{\circ} \mathrm{C}$ - температура испытаний.

\section{Квантово-химические расчеть}

Для оценки дипольных моментов и поляризуемости были выполнены квантовохимические расчеты молекул с использованием пакета программ PC GAMESS [14]. Оптимизация геометрии, а также расчет силового поля и частот колебаний молекул выполнены методами AM1 и DFT (гибридный функционал B3LYP) [15] с использованием базисного набора 631(d,p) [16, 17]. В связи с тем, что при расчетах поляризуемости и дипольных моментов методом DFT результаты, как правило, завышены, была проведена оценка дипольных моментов методом AM1 для структур, оптимизированных методом DFT [18]. Подготовка данных для расчета и обработка результатов осуществлялись с помощью программы ChemCraft [19].

\section{Динамический механический анализ}

Динамические испытания проводили на прибope Eplexor $25 \mathrm{~N}$ (NETZSCH) в режиме сжатия c регистрацией действительной части модуля E' и тангенса угла механических потерь $\operatorname{tg} \delta$. Частотные измерения проводили при $25{ }^{\circ} \mathrm{C}$ в диапазоне от 1 до 1000 Ц с шагом 10 Гц. Температурные измерения - при частоте 1 Гц с шагом 1 К/мин.

\section{Определение упругопрочностных свойств при растяжении}

Стандартные образцы в форме двухсторонней лопатки испытывали на разрывной машине согласно ГОСТ ISO 37-2013 [20].

\section{Набухание каучуков и вулканизатов}

Сорбцию 1,2-дихлорэтана образцами каучуков и вулканизатов изучали весовым методом при $50{ }^{\circ} \mathrm{C}$. Степень сорбции (набухания) $\alpha$ определяли по уравнению:

$$
\alpha=\left(\mathrm{m}-\mathrm{m}_{\mathrm{o}}\right) / \mathrm{m}_{\mathrm{o}},
$$

где $\mathrm{m}$ - масса набухшего образца; $\mathrm{m}_{\mathrm{o}}$ - масса исходного образца.

Плотность цепей сетки можно оценить по данным равновесного набухания вулканизатов [21, 22]. Из резиновой пластины вырезали образцы диаметром 1см и погружали в 1,2 - дихлорэтан. Через определенные интервалы времени образцы извлекали, поверхность осушали фильтровальной бумагой, взвешивали с точность 0,0001 г. Объемную долю каучука в набухшем вулканизате $\mathrm{V}_{\mathrm{r}}$ определяли по уравнению:

$$
\mathrm{V}_{\mathrm{r}}=\left[\frac{\rho_{\mathrm{r}}}{\rho_{\mathrm{s}}}\left(\mathrm{W}_{\mathrm{s}}-\frac{\mathrm{W}_{\mathrm{o}}}{\mathrm{W}_{\mathrm{s}}}\right)+1\right]^{-1},
$$

где $\mathrm{W}_{\mathrm{o}}$ - масса ненабухшего каучука, $\mathrm{W}_{\mathrm{s}}$ - масса набухшего каучука, $\rho_{\mathrm{r}}$ - плотность каучука, $\rho_{\mathrm{s}}-$ плотность растворителя.

Молекулярную массу цепей сетки определяли по уравнению:

$$
\frac{1}{M_{c}}=-\left(\frac{\ln \left(1-V_{r}\right)+V_{r}+\chi \cdot V_{r}^{2}}{\rho_{r} \cdot V_{s}\left(V_{r}^{1 / 3}-0,5 V_{r}\right)}\right),
$$

где константа Хаггинса $\chi$ рассчитана по формуле Крауса $\chi=0,37+0,52 \mathrm{~V}_{\mathrm{r}}, \mathrm{V}_{\mathrm{r}}$ - молярный объем растворителя. 
Степень поперечного сшивания $\rho_{\mathrm{r}} / \mathrm{M}_{\mathrm{c}}$ и число цепей сетки в единице объема $\mathrm{N}_{c}$ рассчитано по формуле: $\rho_{\mathrm{r}} / \mathrm{M}_{\mathrm{c}}=\mathrm{N}_{\mathrm{c}} / \mathrm{N}_{\mathrm{A}}$, где $\mathrm{N}_{\mathrm{A}}-$ число Авогадро.

\section{Результаты и их обсуждение}

Физические характеристики полимеров вообще и эластомеров в частности зависят от их молекулярного строения, определяющего два фундаментальных свойства: гибкость цепи и интенсивность внутри- и межмолекулярных взаимодействий [23]. Оба эти параметра зависят от стерических взаимодействий, поляризуемости и полярности элементарных звеньев цепи полимера. Если стерические факторы непосредственно связаны с размерами и объемом молекулярных фрагментов и могут быть оценены, исходя из их строения, то полярность и поляризуемость требуют специального исследования.

\section{Квантово-химические расчеть структуры фторкаучуков}

В настоящей работе были проведены квантово-химические расчеты молекулярных моделей фрагментов сополимерных фторкаучуков, определены их оптимизированные структуры, рассчитаны дипольные моменты и поляризуемость (см. экспериментальную часть). Результаты расчетов приведены на рис. 1.

Анализ данных рис. 1 показывает, что значения поляризуемости фрагментов всех фторкаучуков отличаются незначительно. Это позволяет предположить, что интенсивность внутри- и межмолекулярных дисперсионных взаимодействий с участием этих каучуков должна быть близка. В свою очередь результирующие дипольные моменты каучуков существенно различаются. Прежде всего, это касается сополимера 1000 Р, дипольный момент (ДМ) которого $(0,246$ D) существенно ниже по сравнению с ДМ сополимера СКФ-26 $(3,08 \mathrm{D})$ и терполимеров 7065 и $3061 \mathrm{M}(2,71 \mathrm{D})$.

Особенностью перфторированного сополимеpa 1000 Р является отсутствие в структуре винилиденфторидных элементарных звеньев, которые присутствуют у всех остальных каучуков. Полярные свойства фторкаучуков в основном определяются наличием большого числа групповых диполей сильнополярных связей -C-F. При практически неупорядоченном (изотропном) расположении векторов этих связей в пространстве происходит компенсация диполей и снижение результирующего дипольного момента, что и наблюдается в случае 1000 P (рис. 1). В структуре остальных каучу- ков присутствует винилиденфторидный фрагмент $-\mathrm{CH}_{2}-\mathrm{CF}_{2}$-, значительный дипольный момент которого, направленный от метиленовой к дифторметиленовой группе, нескомпенсирован. Это и обеспечивает существенную полярность каучуков СКФ-26, 7065 и 3061Р. Следует отметить, что слабая полярность молекулярных звеньев 1000Р может и не обеспечивать автоматически наибольшую молекулярную гибкость этого каучука, поскольку он обладает в ряду исследованных сополимеров и наиболее объемным заместителем $\mathrm{C}-\mathrm{OCF}_{3}$, который способен вследствие стерических взаимодействий повышать потенциальный барьер вращения вокруг связей $-\mathrm{C}-\mathrm{C}-$ и, тем самым увеличивать кинетическую жесткость макромолекулы.

\section{Динамический механический анализ каучуков и вулканизатов}

Известно, что динамический механический анализ (ДМА) является одним из наиболее информативных методов исследования деформационных и теплофизических свойств полимеров. В связи с этим были проведены исследования влияния частоты колебаний и температуры на действительную часть модуля Е' и тангенс угла механических потерь $\operatorname{tg} \delta$ всех исследуемых фторкаучуков и резин на их основе. На рис. 2 приведены соответствующие зависимости для фторкаучуков СКФ-26 и Элафтор 1000Р и их вулканизатов.

Анализ данных, представленных на рисунках, показывает, что на зависимости $\operatorname{tg} \delta(f)$ в области частот 400-1000 Гц проявляются пики различной интенсивности. Следует отметить, что прямое отнесение вышеупомянутых максимумов к конкретным релаксационным процессам представляется затруднительным в связи со сложностью молекулярного строения и надмолекулярной структуры исследованных сополимеров. Для облегчения анализа частотных зависимостей в табл. 1 приведены их основные характеристики в виде значений частот максимумов, модуля упругости и тангенса угла механических потерь.

Данные, представленные на рис. 2 и в табл. 1, свидетельствуют о наличии общих полос поглощения энергии колебаний: 421, 491, 511 Гц . Это указывает на существование однотипных релаксационных процессов с участием молекулярных фрагментов близких размеров и массы [24].

Целесообразно проанализировать поведение наиболее низкочастотного пика 421 Гц, общего для всех каучуков и характеризующего релаксационный процесс с участием наибольшего по размеру релаксирующего элемента. При этом обращает внимание наименьшее значение модуля E' 


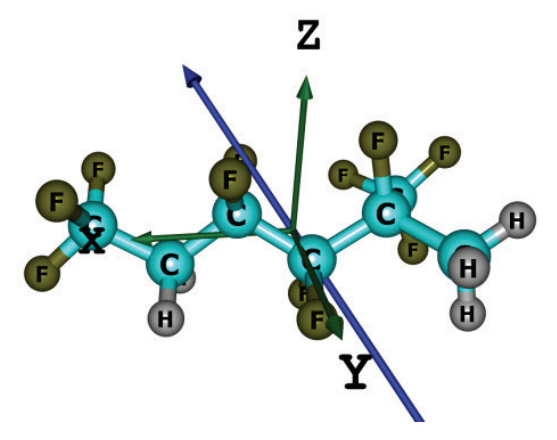

СКФ-26 сополимер винилиденфторида и гексафторпропилена

\begin{tabular}{|c|c|c|c|c|}
\hline & & \multicolumn{2}{|c|}{$\left(-\mathrm{CF}_{2}-\mathrm{CF}_{2}-\right)_{\mathrm{n}}-\left(-\mathrm{CF}-\mathrm{CF}_{2}-\right)_{\mathrm{m}}-$} & )$_{m}-$ \\
\hline$\mu \mathrm{x}$ & $\mu y$ & $\mu \mathrm{z}$ & $\mu, D$ & \\
\hline$-1,370$ & 2,116 & $-1,775$ & 3,083 & \\
\hline$\alpha x x$ & $\alpha y y$ & $\alpha z z$ & $\alpha$ iso & $\mathrm{cm}^{3} 10^{24}$ \\
\hline 10,7 & 9,3 & 9,1 & 9,7 & \\
\hline
\end{tabular}
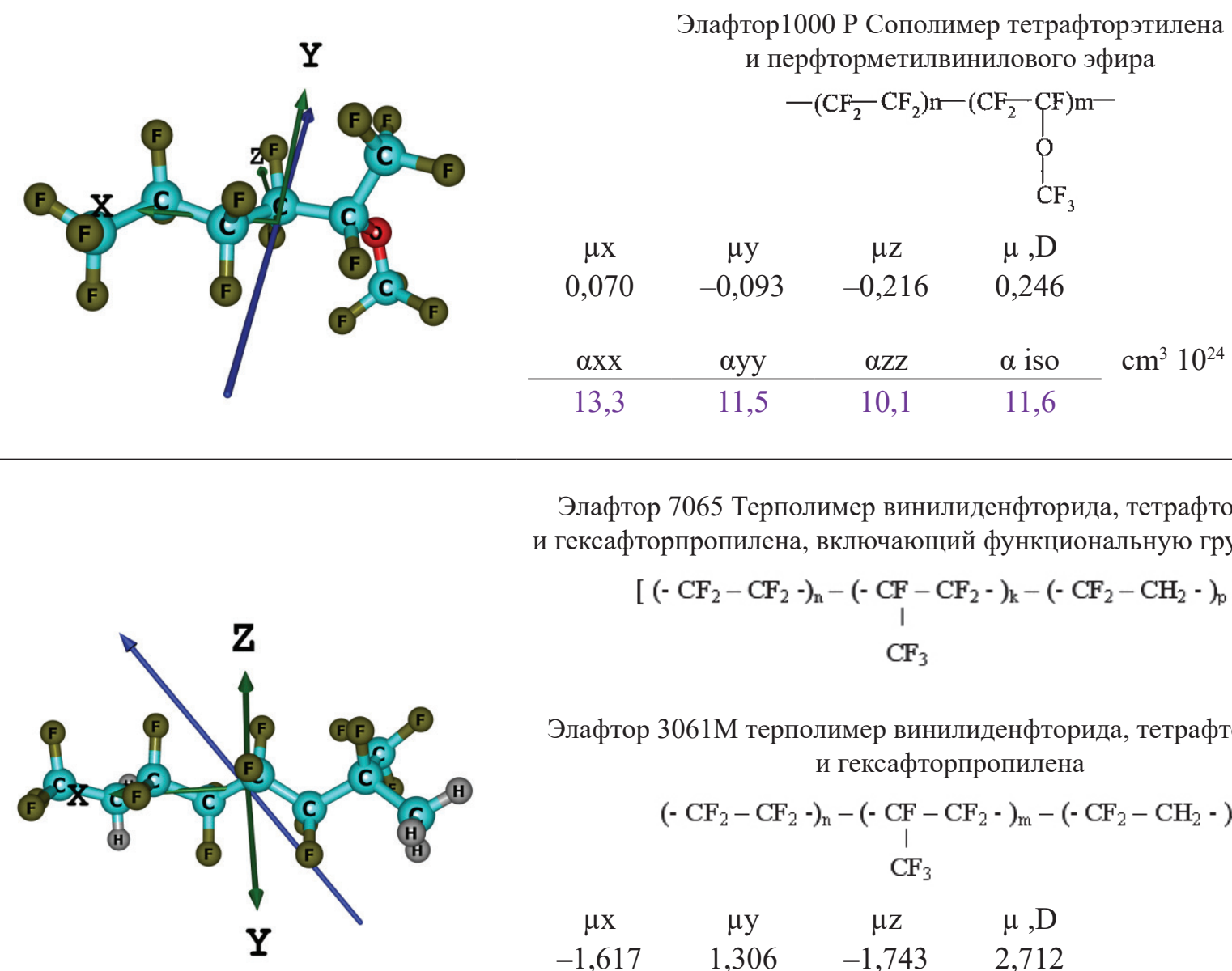

Элафтор 7065 Терполимер винилиденфторида, тетрафторэтилена и гексафторпропилена, включающий функциональную группу (CSM)

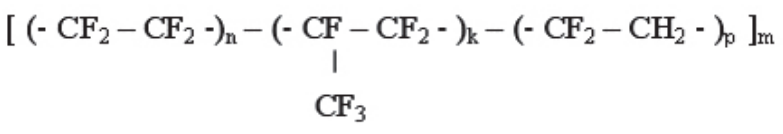

Элафтор 3061М терполимер винилиденфторида, тетрафторэтилена и гексафторпропилена

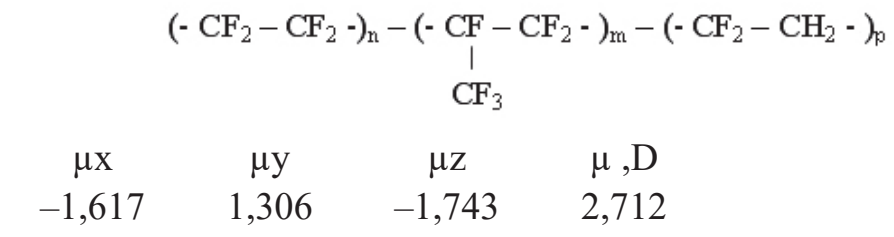

\begin{tabular}{cccc}
$\alpha \mathrm{xx}$ & $\alpha y \mathrm{y}$ & $\alpha \mathrm{zz}$ & $\alpha$ iso \\
\cline { 1 - 3 } & $\mathrm{cm}^{3} 10^{24}$
\end{tabular}

Рис. 1. Оптимизированные структуры фрагментов фторкаучуков, их дипольные моменты и поляризуемость

18,38 МПа каучука ELAFTOR 100Р при 421 Гц. Высокая гибкость цепи этого эластомера не вызывает удивления, т.к. в ходе квантово-химических расчетов (рис. 1) была установлена его наименьшая полярность в ряду исследованных каучуков, а значит и наиболее слабые внутри- и межмолекулярные диполь-дипольные взаимодействия, ответственные за ограничения молекулярной подвижности.
Наиболее интересно проанализировать влияние вулканизации каучуков на параметры ДМАспектров. Эти данные (табл. 1) показывают, что этот процесс не сопровождается существенным изменением частот фиксируемых максимумов поглощения колебательной энергии, но при этом заметно (в 2-3 раза) повышается модуль упругости. Это свидетельствует о том, что релаксацион- 

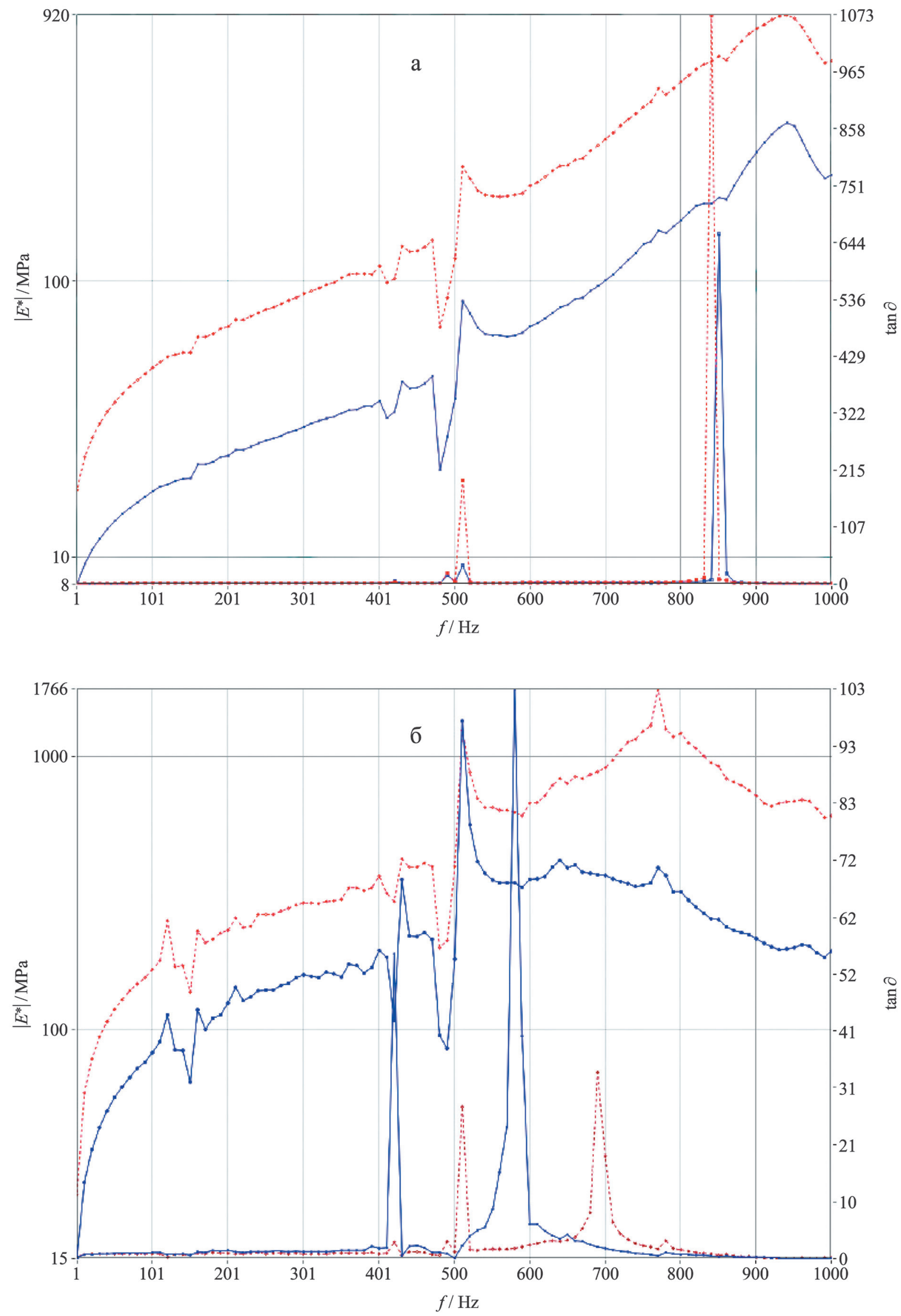

Рис. 2. Зависимости модуля упругости и тангенса угла механических потерь от частоты колебаний при $25{ }^{\circ} \mathrm{C}$ а-для СКФ-26 (-) и вулканизата (---); б - для Элафтор $1000 P$ (-) и вулканизата (---) 
Параметры частотных зависимостей DMA

\begin{tabular}{|c|c|c|c|c|c|c|c|c|c|c|}
\hline & $\begin{array}{c}\text { f, } \\
\Gamma_{\mathbf{L}}\end{array}$ & $\begin{array}{c}\mathrm{E}, \\
\mathrm{M \Pi a} / \operatorname{tg} \delta\end{array}$ & $\begin{array}{l}\mathbf{f}, \\
\Gamma \mathbf{u}\end{array}$ & $\begin{array}{c}\text { E, } \\
\mathrm{M \Pi a} / \operatorname{tg} \delta\end{array}$ & $\begin{array}{l}\mathbf{f}, \\
\Gamma \mathbf{u}\end{array}$ & $\begin{array}{c}\text { E, } \\
\mathrm{M \Pi a} / \operatorname{tg} \delta\end{array}$ & $\begin{array}{l}\mathbf{f}, \\
\Gamma \mathbf{u}\end{array}$ & $\begin{array}{c}\text { E, } \\
\mathrm{M \Pi a} / \operatorname{tg} \delta\end{array}$ & $\begin{array}{l}\mathbf{f}, \\
\Gamma ц\end{array}$ & $\begin{array}{c}E, \\
M \Pi a / \operatorname{tg} \delta\end{array}$ \\
\hline СКФ26 & 421 & $\begin{array}{c}33,62 / \\
\mathbf{4 , 8 2}\end{array}$ & 491 & $\begin{array}{l}27,39 / \\
\mathbf{1 7 , 0 8}\end{array}$ & 511 & $\begin{array}{l}84,58 / \\
\mathbf{3 5 , 4 6}\end{array}$ & 851 & $\begin{array}{l}200,37 / \\
\mathbf{6 5 9 , 8 3}\end{array}$ & & \\
\hline $\begin{array}{l}\text { СКФ26 } \\
\text { вулк }\end{array}$ & 421 & $\begin{array}{c}102,18 / \\
\mathbf{4 , 5 1}\end{array}$ & 491 & $\begin{array}{c}87 / \\
\mathbf{2 1 , 3 5}\end{array}$ & 511 & $\begin{array}{l}259,32 / \\
\mathbf{1 9 5 , 0 9}\end{array}$ & 841 & $\begin{array}{c}622,2 / \\
1072,77\end{array}$ & & \\
\hline $\begin{array}{l}\text { ELAFTOR } \\
100 \mathrm{P}\end{array}$ & 421 & $\begin{array}{l}18,38 / \\
\mathbf{5 5 , 3 4}\end{array}$ & & & & & 581 & $\begin{array}{l}345,11 / \\
\mathbf{1 0 3 , 4 4}\end{array}$ & & \\
\hline $\begin{array}{l}\text { ELAFTOR } \\
\text { 100Р вулк. }\end{array}$ & 421 & $\begin{array}{c}295,08 / \\
\mathbf{2 , 9 9}\end{array}$ & 491 & $\begin{array}{c}212,32 / \\
\mathbf{3 , 1 3}\end{array}$ & 511 & $\begin{array}{c}1246,97 / \\
\mathbf{2 7 , 5 6}\end{array}$ & 691 & $\begin{array}{c}879,91 / \\
\mathbf{3 3 , 8 3}\end{array}$ & 781 & $\begin{array}{c}1262,25 / \\
\mathbf{3 , 2 2}\end{array}$ \\
\hline $\begin{array}{l}\text { ELAFTOR } \\
3061 \mathrm{M}\end{array}$ & 421 & $\begin{array}{c}38,25 / \\
\mathbf{3 , 3 6}\end{array}$ & & & 511 & $\begin{array}{c}91,16 / \\
\mathbf{9 , 7 9}\end{array}$ & 841 & $\begin{array}{c}227,23 / \\
\mathbf{2 9 , 7}\end{array}$ & & \\
\hline $\begin{array}{l}\text { ELAFTOR } \\
\text { 3061М вулк. }\end{array}$ & 421 & $\begin{array}{c}99,88 / \\
\mathbf{2 , 3 7}\end{array}$ & 471 & $\begin{array}{c}104,32 / \\
\mathbf{0 , 9 7}\end{array}$ & 511 & $\begin{array}{c}190,12 / \\
\mathbf{6 , 4 1}\end{array}$ & 861 & $\begin{array}{c}534,57 / \\
\mathbf{1 5 , 0 2}\end{array}$ & & \\
\hline $\begin{array}{l}\text { ELAFTOR } \\
7005\end{array}$ & 421 & $\begin{array}{c}49,30 / \\
\mathbf{4 , 6 9}\end{array}$ & 491 & $\begin{array}{c}46,46 / \\
7,28\end{array}$ & 511 & $\begin{array}{c}171,5 / \\
\mathbf{6 , 3 9}\end{array}$ & 711 & $\begin{array}{l}189,37 / \\
\mathbf{2 4 4 , 4 2}\end{array}$ & 781 & $\begin{array}{c}244,24 / \\
\mathbf{1 1 , 8 3}\end{array}$ \\
\hline $\begin{array}{l}\text { ELAFTOR } \\
7005 \text { вулк. }\end{array}$ & 421 & $\begin{array}{c}126,72 / \\
\mathbf{3 , 9 4}\end{array}$ & 491 & $\begin{array}{c}108,82 / \\
\mathbf{1 0 , 8 8}\end{array}$ & 511 & $\begin{array}{c}385,28 / \\
\mathbf{2 0 , 5 3}\end{array}$ & 761 & $\begin{array}{c}648,69 / \\
\mathbf{2 8 , 7 7}\end{array}$ & 791 & $\begin{array}{c}691,38 / \\
\mathbf{1 9 , 8 6}\end{array}$ \\
\hline
\end{tabular}

ные элементы по размеру значительно меньше, чем фрагменты макромолекул между узлами вулканизационной сетки. Однако ее наличие приводит к увеличению жесткости релаксирующих элементов за счет ограничения их подвижности поперечными связями.

При этом наименее полярный каучук Элафтор 1000Р при вулканизации демонстрирует наиболее сильное изменение параметров низкочастотного релаксационного процесса при 421 Гц. Так, при структурировании этого сополимера его жесткость (модуль Е') увеличивается не в 2-3 раза, а в 16 раз! Одновременно тангенс $\operatorname{tg} \delta$, характеризующий вибропоглощение, падает в 18 раз (табл. 1). Для объяснения такого поведения следует иметь ввиду, что и до вулканизации надмолекулярная структура каучуков представляет собой сетку зацеплений с физическими, преимущественно диполь-дипольными контактами в узлах [24]. Наименее полярный каучук Элафтор 1000Р по-видимому обладает наиболее редкой и рыхлой физической сеткой по сравнению с его остальными полярными аналогами. Поэтому его вулканизация, как переход к химической сетке сопровождается наиболее драматическими изменениями релаксационных процессов.

Метод ДМА позволяет получать весьма ценную информацию не только о физико-химиче- ских параметрах полимерной структуры, но определять ее теплофизические характеристики. В связи с этим были получены температурные зависимости модуля Е' и тангенса $\operatorname{tg} \delta$ каучуков СКФ-26 и Элафтор 7005, а также вулканизатов на их основе ( рис. 3 и 4). Результаты обработки этих кривых приведены в табл. 2.

Данные рис. 3 и рис. 4 свидетельствуют о протекании релаксационного $\alpha$-перехода (расстекловывания) обоих каучуков и их вулканизатов, сопровождающегося значительным (на 2 порядка) снижением модуля упругости и появлением максимума на кривой $\operatorname{tg} \delta=\mathrm{f}(\mathrm{T})$. Абсцисса последнего характеризует температуру стеклования эластомеров [23], значения которой приведены в табл. 2. Эти данные позволяют проанализировать влияние вулканизации на динамические и теплофизические характеристики исследованных каучуков.

Так, структурирование каучуков и появление редкой пространственной сетки приводит к 1,5....3-кратному росту модуля упругости полимера в стеклообразном состоянии и 1,5..2-кратному повышению Е' в высокоэластическом состоянии. При этом температуры стеклования повышаются незначительно (табл. 2), симбатно слабому снижению $\operatorname{tg} \delta$, что свидетельствует о несущественном ограничении свободы сегментов. 

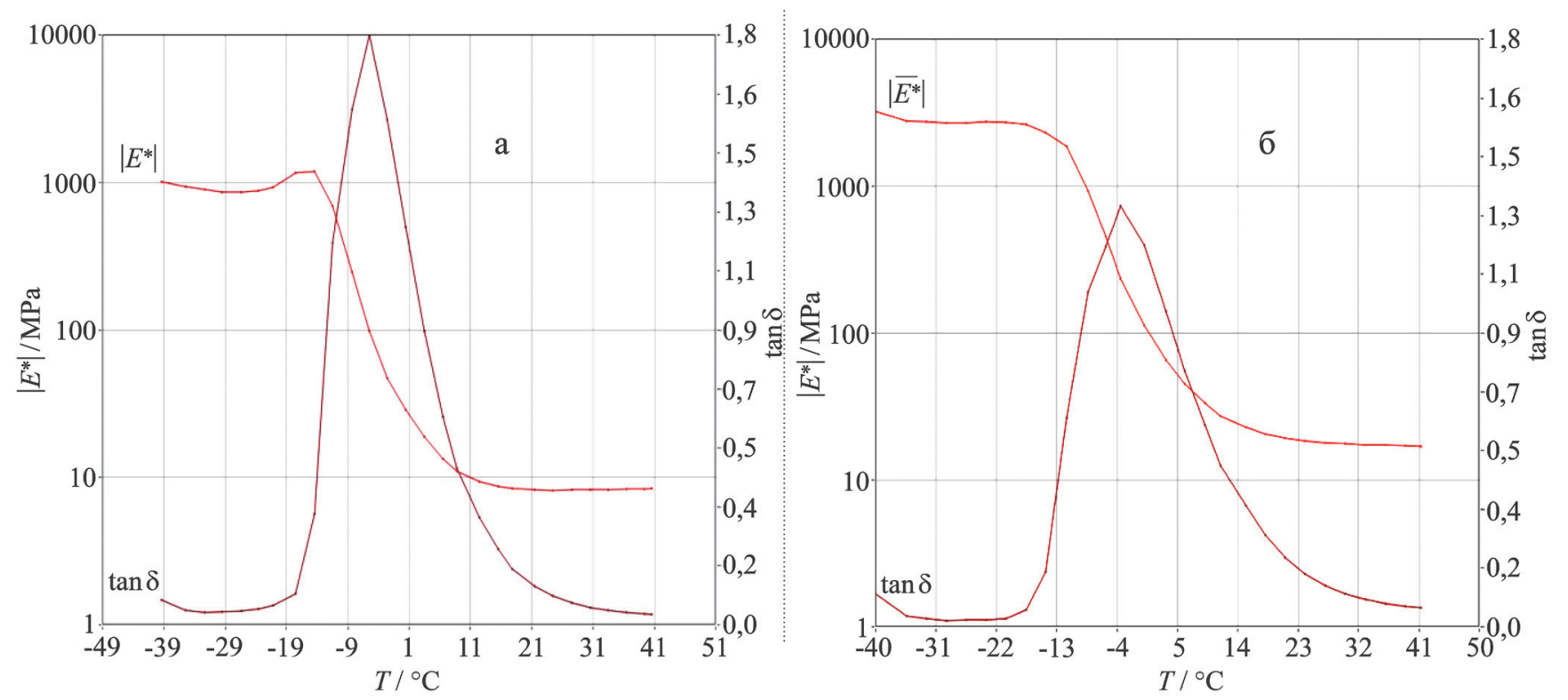

Рис. 3. Температурные зависимости $\mathbf{E}^{\prime}$ и $\operatorname{tg} \delta$ при частоте 1 Гц a-для фторкаучука СКФ-26; б - для вулканизата СКФ-26
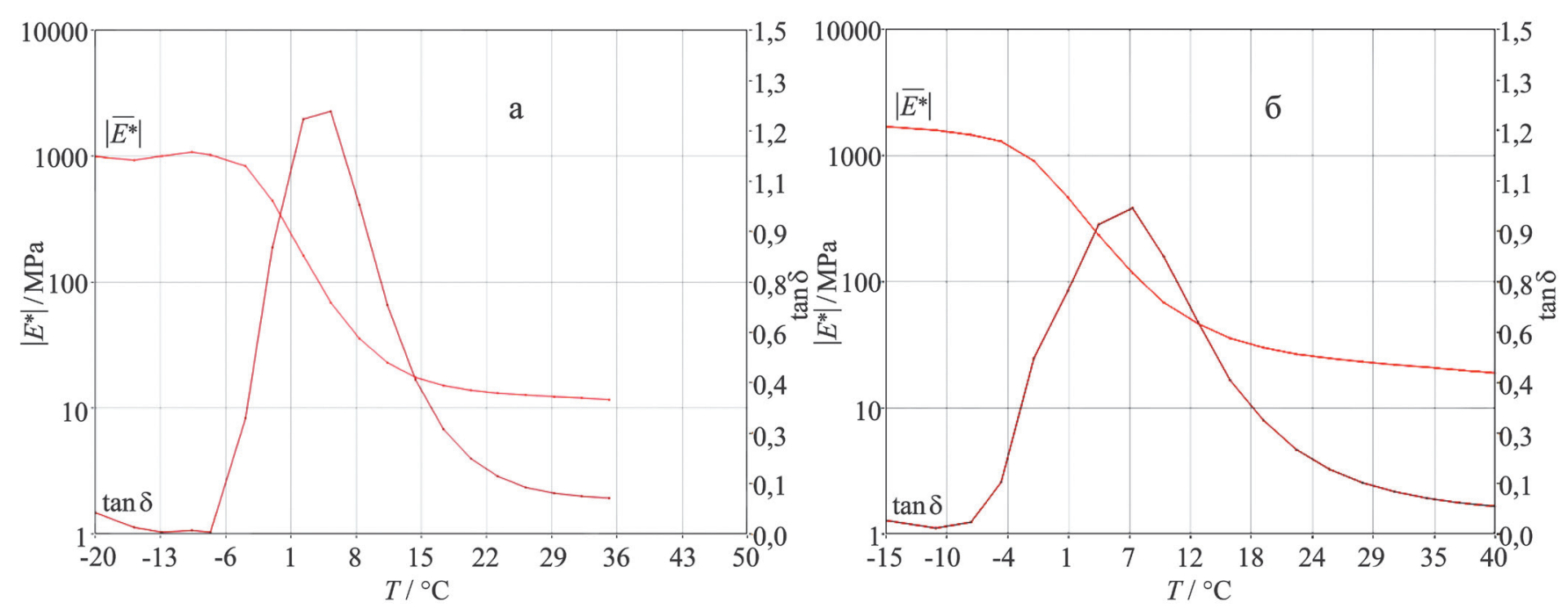

Рис. 4. Температурные зависимости $\mathbf{E}^{\prime}$ и $\operatorname{tg} \delta$ при частоте 1 Гц

а-для фторкаучука марки Элафтор 7005; б - для вулканизата Элафтор 7005

Таблица 2

DMA -параметры каучуков и вулканизатов на их основе

\begin{tabular}{lcccc}
\hline \multicolumn{1}{c}{ Эластомер } & $\mathbf{E}$, МПа $\left({ }^{\circ} \mathbf{C}\right)$ & $\mathbf{E},, \mathbf{M \Pi а}\left({ }^{\circ} \mathbf{C}\right)$ & $\mathbf{T}_{\mathbf{c}},{ }^{\circ} \mathbf{C}$ & $(\operatorname{tg} \delta)$ \\
\hline СКФ-26 & $970(-29)$ & $8,3(+40)$ & $-5,9$ & 1,82 \\
СКФ-26 вулк. & $2730(-29)$ & $17,4(+40)$ & $-3,6$ & 1,30 \\
Элафтор 7005 & $1003(-10)$ & $12,3(+34)$ & 5,3 & 1,26 \\
Элафтор 7005 вулк. & $1582(-10)$ & $20,0(+34)$ & 7,2 & 0,97 \\
\hline
\end{tabular}


Свойства резин, полученных из фторкаучуков

\begin{tabular}{lcccc}
\hline \multicolumn{1}{c}{ Каучук } & $\begin{array}{c}\text { Вязкость по Муни } \\
\left(\mathbf{M L}\left(\mathbf{1 + 1 0 ) 1 2 1}{ }^{\circ} \mathbf{C}\right)\right.\end{array}$ & $\begin{array}{c}\text { Прочность, } \\
\text { Мпа }\end{array}$ & $\begin{array}{c}\text { Удлинение, } \\
\mathbf{\%}\end{array}$ & $\begin{array}{c}\text { ОДС, } \\
\mathbf{2 0 0}{ }^{\circ} \mathbf{C} \cdot 70 \\
\text { час }\end{array}$ \\
\hline $1000 \mathrm{p}$ & 49 & 22,7 & 149 & 20,8 \\
7005 & 60 & 23,1 & 246 & 24,3 \\
$3061 \mathrm{M}$ & 62 & 15,9 & 261 & 25,3 \\
СКФ-26 & 106 & 19,3 & 206 & 12,1 \\
\hline
\end{tabular}

Физико-механические свойства резин на основе фторкаучуков

Деформационные и прочностные свойства эластомеров являются основными при оценке возможности их применения в реальных условиях эксплуатации. В связи с этим в настоящей работе были проведены исследования прочности при растяжении и удлинения при разрыве вулканизатов исследованных фторкаучуков, а также вязкости по Муни и остаточной деформации при сжатии (см. экспериментальную часть). Полученные результаты приведены в табл. 3.

Анализ этих данных показывает, что вязкость по Муни резин на основе Элафтор 3061Р и 7005 близки, что, по-видимому, обусловлено одинаковым составом мономерных звеньев (за исключением присутствия в составе 7005 бромсодержащего мономера (SM). Наличие этого сомономерного звена, влияющего на процесс вулканизации, сопровождается увеличением прочности на разрыв и снижением эластичности (удлинения) вулканизатов (табл. 3). Наибольшая вязкость самого полярного образца СКФ-26 и наименьшая вязкость самого низкополярного 1000Р, по-видимому, указывает на значительный вклад диполь-дипольных взаимодействий в сопротивление течению вулканизатов. Интересно, что наиболее полярный эластомер СКФ-26 проявляет и самую высокую устойчивость к остаточным деформациям (низкий ОДС) (табл. 3).

\section{Набухание каучуков и вулканизатов}

Как было показано во введении, одним из основных достоинств вулканизатов на основе фторкаучуков, является их устойчивость в агрессивных средах, в частности в органических растворителях, при повышенной температуре. В связи с этим в настоящей работе была изучена кинетика набухания каучуков и резин в 1,2 -дихлорэтане при $50{ }^{\circ} \mathrm{C}$. Кинетические кривые представлены на рис. 5.

Данные, представленные на рис. 5 и в табл. 4 , убедительно указывают на закономерное снижение сорбции растворителя в результате вулканиза- ции каучуков, что обусловлено снижением сорбционной емкости полимера при возникновении вулканизационной сетки.

В то же время степень набухания очень сильно зависит от строения и мономерного состава каучуков и вулканизатов на их основе. При этом эластомеры (как каучуки, так и резины) по снижению их степени набухания в дихлорэтане располагаются в ряду: СКФ-26 > Элафтор 3061P > Элафтор 7075 > Элафтор 1000Р симбатно уменьшению их полярности (дипольного момента), как это было установлено ранее. Интересно, что значения скорости набухания, рассчитанные из начальных прямолинейных участков кинетических зависимостей (рис. 5), следуют тем же закономерностям, что и равновесная степень сорбции (табл. 4).

Из данных сорбции органического растворителя вулканизатами на основе сополимерных фторкаучуков были рассчитаны параметры вулканизационной сетки по уравнениям, приведенным в экспериментальной части. Результаты расчетов, представленные в табл. 5 , соответствуют изменениям частотных зависимостей Е' при вулканизации (табл. 1).

\section{Выводы}

На основе оценки дипольных моментов фрагментов каучуков квантово-химическим методом показано, что наиболее полярным эластомером является СКФ-26, наименее полярным - Элафтор 1000 p. Установлено, что полярность фторкаучуков обеспечивается присутствием винилиденфторидных звеньев.

Проведен динамический механический анализ фторкаучуков и резин на их основе. Выявлены характеристические частоты релаксационных переходов, проведена оценка влияния состава эластомеров и процесса вулканизации на динамический модуль упругости и тангенс угла механических потерь. На основании анализа температурных зависимостей $\mathrm{E}^{\prime}$ и $\operatorname{tg} \delta$ определены значения модуля упругости каучуков и вулканизатов в стеклообразном и высокоэластическов состоянии, измерены 

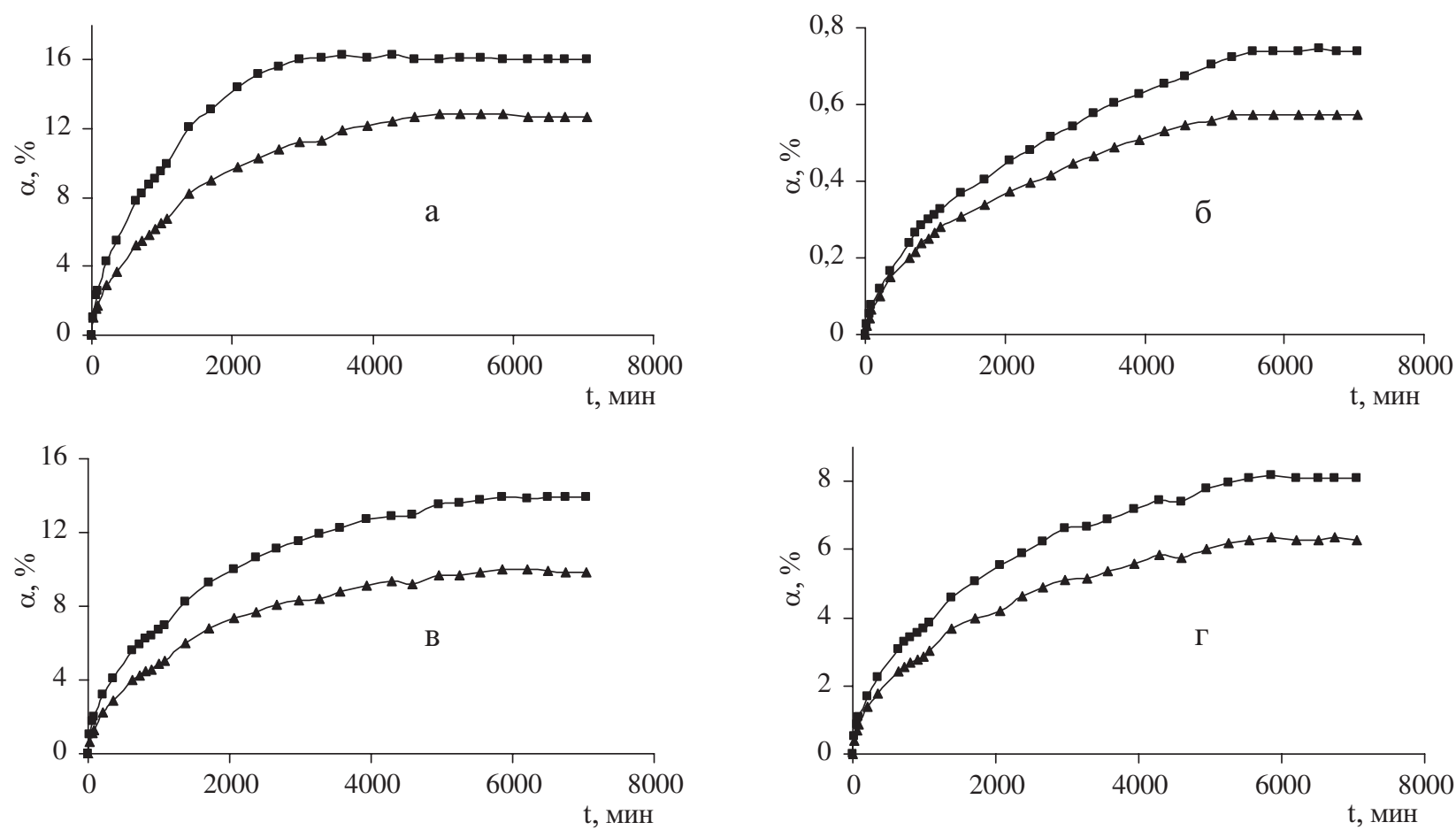

Рис. 5. Кинетические кривые набухания образцов фторкаучуков в 1,2 -дихлорэтане при $\mathbf{t}=\mathbf{5 0}{ }^{\circ} \mathrm{C}$

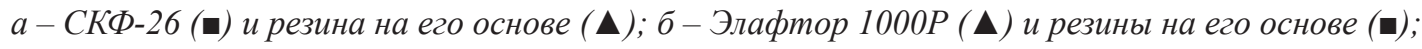

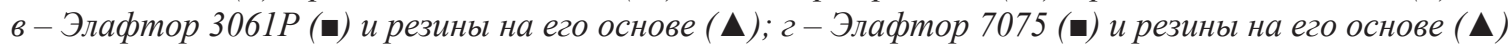

Таблица 4

Равновесная степень набухания и скорость набухания фторкаучуков и их вулканизатов в 1,2 - дихлорэтане

\begin{tabular}{lccccc}
\hline $\begin{array}{c}\text { Образец } \\
\text { фторкаучука }\end{array}$ & $\begin{array}{c}\boldsymbol{\alpha} \\
\mathbf{\%}\end{array}$ & $\begin{array}{c}\text { Скорость } \\
\text { набухания, } \\
\text { \%/мин }\end{array}$ & $\begin{array}{c}\text { Образец резины } \\
\text { на основе } \\
\text { фторкаучука }\end{array}$ & $\begin{array}{c}\text { С, } \\
\text { \% }\end{array}$ & $\begin{array}{c}\text { Скорость } \\
\text { набухания, } \\
\text { \%/мин }\end{array}$ \\
\hline СКФ-26 & 16,02 & 0,039 & СКФ-26 & 12,72 & 0,035 \\
Элафтор 3061 Р & 13,91 & 0,029 & Элафтор 3061 P & 9,87 & 0,018 \\
Элафтор 7075 Р & 8,08 & 0,015 & Элафтор 7075 P & 6,28 & 0,011 \\
Элафтор 1000P & 0,74 & 0,0009 & Элафтор 1000P & 0,58 & 0,0007 \\
\hline
\end{tabular}

Таблица 5

Параметры сетки для вулканизатов на основе фторкаучуков

\begin{tabular}{|c|c|c|c|c|c|c|c|c|c|}
\hline Фторкаучук & $\underset{\Gamma / \mathbf{c m}^{3}}{\rho,}$ & $\begin{array}{c}\mathbf{W}_{0}, \\
\Gamma\end{array}$ & $\begin{array}{c}\mathbf{W}_{\mathrm{s}}, \\
\Gamma\end{array}$ & $\mathbf{V}_{\mathrm{r}}$ & $\chi$ & $\begin{array}{c}1 / \mathbf{M}_{\mathfrak{c}} \\
\text { моль/г }\end{array}$ & $\begin{array}{c}\mathbf{M}_{\mathbf{c}}, \\
\text { г/моль }\end{array}$ & $\begin{array}{c}\text { Степень } \\
\text { поперечного } \\
\text { сшивания } \\
\rho / \mathbf{M}_{c}, \text { моль } / \mathbf{c m}^{3}\end{array}$ & $\begin{array}{c}\text { Число цепей } \\
\text { сетки в ед } \\
\text { объема N } \\
1 / \mathbf{c m}^{3}\end{array}$ \\
\hline СКФ-26 & 1,83 & 1,3366 & 1,5066 & 0,5244 & 0,6427 & 0,00053 & 1875,1 & 0,000976 & $5,8773 \mathrm{E}+20$ \\
\hline Элафтор 3061P & 1,87 & 1,3511 & 1,4844 & 0,5379 & 0,6497 & 0,00057 & 1748,2 & 0,00107 & $6,44182 \mathrm{E}+20$ \\
\hline Элафтор 7075Р & 1,95 & 1,3545 & 1,4396 & 0,5624 & 0,6625 & 0,00065 & 1540,7 & 0,001266 & $7,62205 \mathrm{E}+20$ \\
\hline Элафтор 1000P & 2,05 & 1,3943 & 1,4023 & 0,5991 & 0,6815 & 0,00080 & 1254 & 0,001635 & $9,84447 \mathrm{E}+20$ \\
\hline
\end{tabular}


истинные температуры стеклования. Показано, что вулканизация незначительно влияет на процесс релаксационного $\alpha$-перехода.

Проведены исследования прочности при растяжении и удлинения при разрыве вулканизатов исследованных фторкаучуков, а также вязкости по Муни и остаточной деформации при сжатии. Установлено, что решающее влияние на эти параметры оказывают полярность каучука и параметры вулканизационной сетки.

Изучена кинетика набухания каучуков и резин на их основе в 1,2-дихлорэтане при $50{ }^{\circ} \mathrm{C}$. Показано заметное ограничение сорбции растворителя при возникновении вулканизационной сетки. Установлено, что эластомеры (как каучуки, так и резины) по снижению их равновесной степени и скорости набухания в дихлорэтане располагаются в ряду: СКФ-26 > Элафтор 3061P > Элафтор 7075 > Элафтор 1000Р, симбатно уменьшению их полярности (дипольного момента).

Работа выполнена в рамках Госзадания № FZZW2020-0008. Исследование динамических механических свойств проведено с использованием ресурсов Центра коллективного пользования научным оборудованием ФГБОУ ВО «ИГХТУ».

\section{Лumepamypa}

1. Ameduri B., Boutevin B., Kostov G. Fluoroelastomers: Synthesis, properties and applications. Progress in Polymer Science. 2001. V. 26. P. 105-187. https:// doi.org/10.1016/S0079-6700(00)00044-7.

2. Singh A., Singh Sh., Soni P., Mukherjee N. Non-isothermal Thermogravimetric Degradation Kinetics, Reaction Models and Thermodynamic Parameters of Vinylidene Fluoride Based Fluorinated Polymers. Journal of Macromolecular Science, Part B. 2019. V. 59. P. 1-24. https://doi.org/10.1080/00222348.20 19.1679986.

3. Алифанов Е.В., Чайкун А.М., Наумов И.С., Елисеев O.A. Эластомерные материалы повышенной теплостойкости. Труды ВИАМ. 2017. Т. 50. № 2. С. 41-47. https://doi.org/ 10.18577/2307-6046-2017-0-2-6-6.

4. Бейдер Э. Я., Донской А. А., Железина Г. Ф., Кондрашов Э. К., Сытый Ю. В., Сурнин Е. Г. Опыт применения фторполимерных материалов в авиационной технике. Российский химический журнал. 2008. T. 52. № 3. С. 30-44.

5. Drobny J.G., Moore L.A. Fluoroelastomers Handbook : The Definitive User's Guide second edition. New York: Elsevier Inc. 2005. 373 p.

6. Fernando Reis da Cunha, Irina Davidovich, Yeshayahu Talmon and Bruno Ameduri Emulsion copolymerization of vinylidene fluoride (VDF) with perfluoromethyl vinyl ether (PMVE) Polym. Chem., 2020, N. 11, 24302440. https://doi.org/10.1039/D0PY00059K

7. Нудельман 3. Н. Фторкаучуки: основы, обработка, применение. М.: ООО «ПИФ РИАС», 2007. 384 с.

8. Новицкая С.П., Нудельман 3.Н., Донцова А.А. Фторэластомеры. М.: Химия, 1988. 240 с.

9. Smith D.W. Handbook of Fluoropolymer Science and Technology / D.W. Smith, S.T. Iacono, S.S. Iyer. Wiley. 2014. $670 \mathrm{p}$.

10. Кочеткова Г.В., Логинов Б.А. Новые марки отечественных фторкаучуков. Российский химический журнал. 2008. Т. 52. №3. С. 23-25.

11. Баскин 3.Л., Шабалин Д.А., Выражейкин Е.С., Дедов C.A. Ассортимент, свойства и применение фторполимеров Кирово-Чепецкого химического комбината. Российский химический журнал. 2008. Т. 52. №3. С. 13-23.

12. Cong Fan, Baoyin Li, Mengmeng Ren, Peng Wu, Yang Liu, Teng Chen, Zheng Cheng, Jiaqiang Qin and Xiangyang Liu The reaction kinetics and mechanism of crude fluoroelastomer vulcanized by direct fluorination with fluorine/nitrogen gas. RSC Adv. 2015. N 5, P. 1893218938 https://doi.org/10.1039/C4RA15096A

13. ГОСТ Р ИСО 289-1-2017. Испытания на роторном дисковом вискозиметре ч. 1. Определение вязкости по Муни / М.: Стандартинформ, 2017. - 16 с.

14. Granovsky A.A. PC GAMESS version 7.0, http://classic.chem.msu.su/gran/gamess/index.html.

15. Parr R. G., Yang W. Density-Functional Theory of Atoms and Molecules. - N. Y. Oxford University Press, 1989. 333 p.

16. Becke A.D. J. Chem. Phys. 1993. V.98. P. 5648-5652. https://doi.org/10.1063/1.464913

17. Журко Г.А., Александрийский В.В., Бурмистров $B . A$. Использование квантово-химических расчетов для изучения молекулярной структуры некоторых нематических оснований Шиффа. Жидк. крист. и их практич. использ. 2005. № 1-2. С. 13-23.

18. Aleksandriiskii V.V., Novikov I.V., Kuvshinova S.A., Burmistrov V.A., Koifman O.I. Dielectric, optical and orientational properties of liquid crystalline 4-alkyloxy-4'-cyanoazoxybenzenes and 4-alkyloxy-4'cyanoazobenzenes. J. Mol. Liq. 2016. V. 223. P. 12701276. https://doi.org/10.1016/j.molliq.2016.09.064.

19. Andrienko G.A. Chemcraft, v. 1.8. http://www.chemcraftprog.com.

20. ГОСТ ISO 37-2013 Резина или термопластик. Определение упругопрочностных свойств при растяжении / М.: Стандартинформ, 2014. - 16 с.

21. Методы исследования структуры и свойств полимеров: Учеб. Пособие. И.Ю.Аверко-Антонович, Р.Т. Бикмуллин, КГТУ. Казань, 2002. 604 с.

22. Wong R.S., Ashton M., Dodou K. Effect of Crosslinking Agent Concentration on the Properties of Unmedicated Hydrogels. Pharmaceutics. 2015. N 7. P. 305-319. doi: 10.3390/pharmaceutics 7030305 .

23. Тагер А.А. Физико-химия полимеров / А.А. Тагер; под ред. А. А. Аскадского. Изд. 4., перераб. и доп. М.: Научный мир. 2007. 576 с.

24. Бартенев Г.М. Структура и релаксационные свойства эластомеров. М.: Химия. 1979. 288 с.

\section{References}

1. Ameduri B., Boutevin B., Kostov G. Fluoroelastomers: Synthesis, properties and applications. Progress in Poly- 
mer Science. 2001. V. 26. P. 105-187. DOI: 10.1016/ S0079-6700(00)00044-7.

2. Singh A., Singh Sh., Soni P., Mukherjee N. Nonisothermal Thermogravimetric Degradation Kinetics, Reaction Models and Thermodynamic Parameters of Vinylidene Fluoride Based Fluorinated Polymers. Journal of Macromolecular Science, Part B. 2019. V. 59. P. 1-24. DOI: 10.1080/00222348.2019.1679986.

3. Alifanov E.V., Chaikun A.M., Naumov I.S., Eliseev $O . A$. Elastomeric materials with increased heat resistance. Trudy VIAM. 2017. V. 50. N. 2. P. 41-47. DOI: 10.18577/2307-6046-2017-0-2-6-6.

4. Beider E.Ya., Donskoy A.A., Zhelezina G.F., Kondrashov E.K., Sytyy Yu.V., Surnin E.G. Experience in the use of fluoropolymer materials in aviation technology. Russian Chemical Journal. 2008. V. 52. N. 3. P. 30-44.

5. Drobny J.G., Moore L.A. Fluoroelastomers Handbook: The Definitive User's Guide second edition. New York: Elsevier Inc. 2005. 373 p.

6. Fernando Reis da Cunha, Irina Davidovich, Yeshayahu Talmon and Bruno Ameduri. Emulsion copolymerization of vinylidene fluoride (VDF) with perfluoromethyl vinyl ether (PMVE) Polym. Chem. 2020. N. 11. P. 2430-2440. DOI: 10.1039/D0PY00059K

7. Nudelman Z.N. Fluororubbers: basics, processing, application. Moscow: OOO PIF RIAS. 2007. 384 p.

8. Novitskaya S.P., Nudelman Z.N., Dontsova A.A. Fluoroelastomers. M .: Chimia, 1988.240s.

9. Smith D.W. Handbook of Fluoropolymer Science and Technology / D.W. Smith, S.T. Iacono, S.S. Iyer. Wiley. 2014. $670 \mathrm{p}$.

10. Kochetkova G.V., Loginov B.A. New brands of domestic fluorocarbon rubber. Russian chemical journal. 2008. V. 52. N. 3. P. 23-25.

11. Baskin Z.L., Shabalin D.A., Vyrazheikin E.S., Dedov S.A. Assortment, properties and application of fluoropolymers of the Kirovo-Chepetsk Chemical Plant. Russian Chemical Journal. 2008. V. 52. N. 3. P. 13-23.

12. Cong Fan, Baoyin Li, Mengmeng Ren, Peng Wu, Yang Liu, Teng Chen, Zheng Cheng, Jiaqiang Qin and Xiang- yang Liu. The reaction kinetics and mechanism of crude fluoroelastomer vulcanized by direct fluorination with fluorine/nitrogen gas. RSC Adv. 2015. N 5. P.18932-18938. DOI: 10.1039/C4RA15096A.

13. GOST R ISO 289-1 - 2017 Tests on a rotary disk viscometer, part 1 Determination of Mooney viscosity / M.: Standartinform. 2017. 16 p.

14. Granovsky A.A. PC GAMESS version 7.0, http://classic.chem.msu.su/gran/gamess/index.html.

15. Parr R.G., Yang W. Density-Functional Theory of Atoms and Molecules. - N. Y. Oxford University Press, 1989. 333 p.

16. Becke A.D. J. Chem. Phys. 1993. V. 98. P. 5648-5652. DOI: $10.1063 / 1.464913$

17. Zhurko G.A., Aleksandriiskii V.V., Burmistrov V.A. Using quantum chemical calculations to study the molecular structure of some nematic Schiff bases. Liq. Cryst. and their Appl. 2005. N. 1-2. P. 13-23.

18. Aleksandriiskii V.V., Novikov I.V., Kuvshinova S.A., Burmistrov V.A., Koifman O.I. Dielectric, optical and orientational properties of liquid crystalline 4-alkyloxy-4'-cyanoazoxybenzenes and 4-alkyloxy-4'cyanoazobenzenes. J. Mol. Liq. 2016. V. 223. P. 1270 1276. DOI: 10.1016/j.molliq.2016.09.064.

19. Andrienko G.A. Chemcraft. v. 1.8. http://www.chemcraftprog.com.

20. GOST ISO 37-2013 Rubber or thermoplastic. Determination of elastic strength properties in tension / M.: Standartinform. 2014. 16 p.

21. Methods for studying the structure and properties of polymers: Textbook. Benefit. I.Yu. Averko-Antonovich, R.T.Bikmullin, KSTU. Kazan. 2002. 604 p.

22. Wong R.S., Ashton M., Dodou K. Effect of Crosslinking Agent Concentration on the Properties of Unmedicated Hydrogels. Pharmaceutics. 2015. N 7. P. 305-319. DOI: 10.3390/pharmaceutics 7030305 .

23. Tager A.A. Physical chemistry of polymers / A.A. Tager; ed. A. A. Askadsky. Ed. 4., revised and add. M.: Nauchnyi mir. 2007. 576 p.

24. Bartenev G.M. Structure and relaxation properties of elastomers. M.: Chimia. 1979. 288 p. 